\title{
Applicability of a Voltammetric Assay Based on the Electroreduction of Oxygen to Evaluate the Antioxidant Capacity of Pequi (Caryocar brasiliense Camb.) Pulp
}

\author{
Flávia A. Pinheiro, ${ }^{a, b}$ Leonardo L. Okumura, ${ }^{c}$ Astréa F. S. Silva, ${ }^{c}$ Júnio G. Silva, ${ }^{c}$ \\ Letícia R. Ferreira, ${ }^{b}$ Edilton S. Barcellos ${ }^{c}$ and Edimar A. F. Fontes ${ }^{*, b}$ \\ ${ }^{a}$ Instituto Federal de Educação, Ciência e Tecnologia do Espírito Santo, \\ Campus Venda Nova do Imigrante, 29375-000 Venda Nova do Imigrante-ES, Brazil \\ ${ }^{b}$ Departamento de Tecnologia de Alimentos, Universidade Federal de Viçosa, \\ 36570-000 Viçosa-MG, Brazil
}

'Departamento de Química, Universidade Federal de Viçosa, 36570-000 Viçosa-MG, Brazil

This study aimed to use a differential pulse voltammetric (DPV) assay, based on the electroreduction of oxygen, to evaluate the antioxidant capacity of pequi pulp. The results were expressed in coefficient of antioxidant capacity $(\mathrm{K})$, at different $\mathrm{pH}$ values and in trolox equivalent antioxidant capacity (TEAC), and were compared to the 2,2'-azinobis(3-ethylbenzothiazoline6-sulfonic acid) (ABTS) and 2,2-diphenyl-1-picrylhydrazyl (DPPH) spectrophotometric assays. The principal component analysis showed higher $\mathrm{K}$ for pequi pulp extract and $\mathrm{pH}$ tending to 7.15. The antioxidant capacity was related to the presence of gallic acid in its composition. Regarding the TEAC value, the best result was obtained by the DPV test $\left(53.43 \pm 5.14 \mu\right.$ mol trolox g ${ }^{-1}$ pulp). The pequi pulp showed antioxidant capacity, compared to the standard antioxidant compounds evaluated. It was concluded that the voltammetric protocol was efficient to assess the total antioxidant capacity of pequi pulp and can be an alternative to conventional spectrophotometric assays, for the analysis of food matrices.

Keywords: electrochemical techniques, food analysis, antioxidant capacity, bioactive compounds, pequi

\section{Introduction}

The assessment of the antioxidant potential of foods is carried out by the determination of their antioxidant capacity. Various methodologies are employed for this purpose, especially the spectrophotometric assays, including the 2,2'-azinobis(3-ethylbenzothiazoline6-sulfonic acid) (ABTS) and 2,2-diphenyl-1-picrylhydrazyl (DPPH). ${ }^{1}$ However, these colorimetric methods have some limitations. ${ }^{2,3}$ For example, the samples must undergo a pretreatment to eliminate interfering agents, such as reducing sugars and organic acids. ${ }^{4}$ In fact, each method has its own characteristics, such as the reaction mechanism, types of oxidation substrates, reaction medium (basic, acid or neutral), compound proof of reaction and expression of results. ${ }^{1}$ This hinders the comparison of results obtained by different authors that used different methodologies.

The differences between the reactive species and their forms of activity hinder the development of a simple

*e-mail: eaffontes@ufv.br and universal method to accurately and quantitatively determine the total antioxidant capacity. ${ }^{5}$ Therefore, the use of electrochemical techniques becomes an alternative for this analysis. ${ }^{6}$ The processes of formation and/or stabilization of free radicals are related to oxidationreduction reactions. ${ }^{7}$ Therefore, several studies have used voltammetric electrochemical techniques to assess the antioxidant capacity of foods and isolated compounds, since they improve methodology standardization and increase the amount of information about the compound of interest. ${ }^{6,8-12}$

Voltammetry presents the following advantages over traditional spectrophotometric techniques: low operation and instrumental cost; use of less organic solvents, consequently decreasing waste generation; the analysis can be performed in the sample without pre-treatment for separation/cleaning of the compounds that affect other methods, colored materials or other dispersed solid particles; fast data acquisition, sensitivity and portability. ${ }^{13-17}$

As already described, several studies have applied voltammetric techniques to determine the antioxidant 
capacity of food matrices. However, no study using pequi pulp for this purpose has been found so far.

Pequi (Caryocar brasiliense Camb.) is a typical fruit of the Brazilian cerrado that has not been the subject of scientific investigation. It is an important source of nutrients, whose pulp has about $3.73 \pm 0.01 \mathrm{~g}$ per $100 \mathrm{~g}$ of proteins; $26.15 \pm 0.85 \mathrm{~g}$ per $100 \mathrm{~g}$ of lipids; $58.83 \pm 2.06 \mathrm{mg}$ per $100 \mathrm{~g}$ of calcium; $1.40 \pm 0.59 \mathrm{mg}$ per $100 \mathrm{~g}$ of iron and $2.81 \pm 0.70 \mathrm{mg}$ per $100 \mathrm{~g}$ of zinc. ${ }^{18}$ It also contains bioactive compounds with antioxidant properties, such as vitamin $\mathrm{C}(6.63 \pm 1.02 \mathrm{mg}$ per $100 \mathrm{~g}),{ }^{19}$ phenolic compounds $\left(1.80 \pm 0.04\right.$ to $\left.3.34 \pm 0.07 \mathrm{mg} \mathrm{GAE} \mathrm{g}^{-1}\right)$ and total carotenoids ( $37.08 \pm 1.84$ to $\left.187.00 \pm 12.43 \mu \mathrm{g} \mathrm{g}^{-1}\right){ }^{20}$ Violaxanthin, lutein and zeaxanthin are among the predominant carotenoids observed. ${ }^{21}$

Therefore, this study aimed to verify the applicability of an experimental protocol, based on voltammetry, to evaluate the antioxidant capacity of pequi pulp.

\section{Experimental}

\section{Reagents and solutions}

All reagents used were of analytical grade of purity (P.A.). Acetone, acetic acid, boric acid, phosphoric acid, ethanol, sodium hydroxide and methanol were purchased from Vetec (Duque de Caxias, RJ, Brazil); ABTS, DPPH, potassium persulfate, L-ascorbic acid, citric acid, $p$-coumaric acid, gallic acid, $\alpha$-tocopherol, 2(3)-t-butyl4-hydroxyanisole (BHA), 2,6-di-tert-butyl-4-methylphenol (BHT) and 6-hydroxy-2,5,7,8-tetramethylchroman2-carboxylic acid (trolox) were acquired from SigmaAldrich Chemical Company (St. Louis, MO, USA).

The $0.1 \mathrm{~mol} \mathrm{~L}^{-1}$ Britton-Robinson buffer was used as support electrolyte in the voltammetric analyses, at $\mathrm{pH}$ $2.20,7.15$ and 10.05. It was prepared from $0.1 \mathrm{~mol} \mathrm{~L}^{-1}$ solutions of acetic acid, boric acid and phosphoric acid. The $\mathrm{pH}$ was adjusted with sodium hydroxide solution, $8.0 \mathrm{~mol} \mathrm{~L}^{-1}$, in a pH Meter, model $827 \mathrm{pH}$ lab (Metrohm, Herisau, Switzerland). The solutions of the antioxidant standards used in the electrochemical test were prepared in ethanol, $95 \%$, on the day of the analysis.

\section{Preparation of the pequi pulp extract}

The pequi (Caryocar brasiliense Camb.) pulp was obtained through the processing of fresh fruits from the December 2015 harvest of the municipality of Santana de Pirapama, MG, Brazil, located at 1900'21"'S (latitude), $44^{\circ} 02^{\prime} 35^{\prime \prime} \mathrm{W}$ (longitude). The pulp was obtained with the aid of a depulping machine (depulping machine (Itametal/
NPC Equipamentos, model Bonina 0.25 df, Itabuna, Brazil) and used in the production of the extract, as recommended by Rufino et $a l . .^{22}$ The extract was stored in an amber flask and maintained under freezing $\left(-18^{\circ} \mathrm{C}\right)$ for later defrosting and use.

Instrumentation of the voltammetric electrochemical assay

The voltammetric measurements were performed using a potentiostat/galvanostat, Autolab (Metrohm Pensalab, Utrecht, The Netherlands), in interface with a computer through the General Purpose Electrochemical System (GPES), version 4.9, with a $50 \mathrm{~mL}$ electrochemical cell provided with three electrodes, one gold working electrode having a geometric area of $0.196 \mathrm{~cm}^{2}$; one platinum wire auxiliary electrode and one $\mathrm{Ag} \mid \mathrm{AgCl}, 3.0 \mathrm{~mol} \mathrm{~L}^{-1} \mathrm{KCl}$ reference electrode (Metrohm, Herisau, Switzerland). Following each voltammetric reading, the surface of the working electrode was polished for approximately $1 \mathrm{~min}$, with alumina 0.3 and $0.05 \mu \mathrm{m}$ (Buehler, Lake Bluff, IL, USA) on an alumina polishing pad, rinsed with ultrapure water (resistivity of $18.2 \mathrm{M} \Omega \mathrm{cm}$ at $25^{\circ} \mathrm{C}$ ) from a Milli-Q purification system (Millipore, Bedford, MA, USA).

Voltammetric characterization of pequi pulp and antioxidant standards

The voltammetric profile of the compounds with antioxidant capacity was characterized by cyclic voltammetry $(\mathrm{CV})$, with scanning of anodic direction, ranging from -0.6 to $+1.4 \mathrm{~V}$, at scan rate of $100 \mathrm{mV} \mathrm{s}^{-1}$ and step potential of $2 \mathrm{mV}$. For such, $10.0 \mathrm{~mL}$ of the $0.1 \mathrm{~mol} \mathrm{~L}^{-1}$ Britton-Robinson buffer, $\mathrm{pH} 2.20$, were transferred to the electrochemical cell. Five minutes after the nitrogen gas injection $\left(\mathrm{N}_{2}, 99.9 \%\right.$ purity) (White Martins Gases Industriais Ltda, Juiz de Fora, MG, Brazil), it was added an aliquot of $300 \mu \mathrm{L}$ of the antioxidant standard solution $33.3 \mathrm{mmol} \mathrm{L}^{-1}$ (L-ascorbic acid, citric acid, $p$-coumaric acid, gallic acid, $\alpha$-tocopherol, BHA, BHT and trolox) for the deoxygenation of the solution. Its final concentration in the cell was around $1.0 \mathrm{mmol} \mathrm{L}^{-1}$. Then, $\mathrm{N}_{2}$ was injected for $1 \mathrm{~min}$ to homogenize the mixture.

The pequi pulp was assessed with the addition of $300 \mu \mathrm{L}$ of the extract in replacement of the antioxidant standard solution. It was also performed analysis of the supporting electrolyte solution to verify the presence of some peak.

In addition to the evaluation of the voltammetric profile of the antioxidant compounds at $\mathrm{pH} 2.20$, the $0.1 \mathrm{~mol} \mathrm{~L}^{-1}$ Britton-Robinson buffer was used, at $\mathrm{pH} 7.15$ and 10.05, in the previous procedure, to assess the effect of $\mathrm{pH}$ on the antioxidant capacity. All analyses were performed in triplicate. 
Assessment of the total antioxidant capacity through the electroreduction of oxygen

The methodology used in this study was developed through the application of the differential pulse voltammetric (DPV) technique, based on a research carried out by Korotkova et al. ${ }^{23}$ In order to develop the experimental protocol, preliminary tests were carried out to determine the time corresponding to $\mathrm{O}_{2}$ injection demands to promote the saturation of the supporting electrolyte and its selection. It was also determined the concentration range of some antioxidant standards with improved linearity (not shown in this article). The experimental conditions adopted for the DPV readings were: cathodic direction measurements, ranging from 0 to $-0.6 \mathrm{~V}$, pulse amplitude of $100 \mathrm{mV}$, scan rate of $20 \mathrm{mV} \mathrm{s}^{-1}$ and modulation time of $2 \mathrm{~ms}$.

Molecular oxygen $\left(\mathrm{O}_{2}\right)$ was used as oxidant for being a strong oxidizing agent $\left(\mathrm{E}^{\mathrm{o}}=1.229 \mathrm{~V}\right)^{24}$ and one of the most important radicals found in our biological system. At ground state, $\mathrm{O}_{2}$ is a diradical with one unpaired electron in each oxygen. As a radical, it can abstract hydrogen atoms, similarly to the combustion and autoxidation reactions, or work as an electron receptor in biological systems. ${ }^{25}$

$10.0 \mathrm{~mL}$ of $0.1 \mathrm{~mol} \mathrm{~L}^{-1}$ Britton-Robinson buffer ( $\mathrm{pH} 2.20$, 7.15 and 10.05) were transferred to the electrochemical cell. Following saturation with $\mathrm{O}_{2}$ for 5 min (industrial oxygen, purity $>90 \%$ ) (White Martins Gases Industriais Ltda, Juiz de Fora, MG, Brazil), the cathodic peak current of the oxygen (oxidizing agent) was read, without antioxidant addition (control). Then, this solution received the addition of aliquots of $50 \mu \mathrm{L}$ of $0.02 \mathrm{~mol} \mathrm{~L} \mathrm{~L}^{-1}$ antioxidant standard solution (solution for the use of L-ascorbic acid, citric acid, $p$-coumaric acid, gallic acid, $\alpha$-tocopherol, BHA, BHT and trolox), so that its concentration in the cell ranged between 0.1 and $0.6 \mathrm{mmol} \mathrm{L}^{-1}$. A manual homogenization was conducted and after the solution remained at rest for $1 \mathrm{~min}$, the voltammetric measurement was performed. A similar procedure was adopted in the analysis of the pequi pulp extract, with the addition of successive $50 \mu \mathrm{L}$ aliquots of the undiluted extract, which replaced the standard antioxidant solution.

The residual current, inherent to the supporting electrolyte, was determined through voltammetric reading of the $0.1 \mathrm{~mol} \mathrm{~L}^{-1}$ Britton-Robinson buffer ( $\mathrm{pH} 2.20$, 7.15 and 10.05), after an injection of $\mathrm{N}_{2}$ for $10 \mathrm{~min}$. The voltammetric measurements were carried out in duplicate, and the experiment was conducted with three replications. The baseline of the voltammograms was corrected through the moving average, using the tool available in the GPES software system, version 4.9. The voltammograms were plotted with the aid of the OriginPro $8^{\circledR}$ software. ${ }^{26}$
A graphic of $\left(\mathrm{I}_{\mathrm{pc}}-\mathrm{I}_{\mathrm{res}}\right) /\left(\mathrm{I}_{\mathrm{p} 0}-\mathrm{I}_{\mathrm{res}}\right)=\mathrm{f}$ (volume of the antioxidant standard or volume of pequi extract) was developed based on the averages of the cathodic oxygen current obtained for each concentration of the antioxidant standard or pequi extract, where: $I_{p c}$ is the peak cathodic current of $\mathrm{O}_{2}$, in the presence of compound with antioxidant capacity; $\mathrm{I}_{\text {res }}$ is the peak cathodic current of the deoxygenated supporting electrolyte, and $\mathrm{I}_{\mathrm{p} 0}$ is the initial peak cathodic current of $\mathrm{O}_{2}$, without the addition of antioxidant compound. The current decay curve was also observed. The antioxidant capacity of the pequi pulp extract and the antioxidant standards were expressed as antioxidant capacity coefficient $(\mathrm{K})$, which is the angular coefficient of the curve.

In addition to the $\mathrm{K}$ value, the antioxidant capacity of the pequi pulp was expressed as trolox equivalent antioxidant capacity, given by the TEAC value ( $\mu$ mol trolox $\mathrm{g}^{-1}$ pequi pulp). For such, we used the results of cathodic current of oxygen, $\mathrm{pH} 7.15$, obtained by the voltammetric protocol previously described, with pequi pulp concentration ranging from 5 to $30 \mathrm{~mL} \mathrm{~L}^{-1}$ and trolox (antioxidant standard) ranging from 100 to $600 \mu \mathrm{mol} \mathrm{L}^{-1}$.

\section{Spectrophotometric assay of the radical cation ABTS ${ }^{*}$}

The determination of the antioxidant capacity by the ABTS test was performed according to the methodology described by Re et al. ${ }^{27}$ with modifications. In an amber container, $5 \mathrm{~mL}$ of $7.0 \mathrm{mmol} \mathrm{L}^{-1}$ ABTS solution were added to $5 \mathrm{~mL}$ of $2.45 \mathrm{mmol} \mathrm{L}^{-1}$ potassium persulfate solution, which remained protected from light for 12 to $16 \mathrm{~h}$ for the generation of $\mathrm{ABTS}^{\cdot+}$ cation chromophore. Then, the radical solution was diluted in $80 \%$ ethanol until reaching an absorbance of $0.700 \pm 0.005$, at wavelength of $734 \mathrm{~nm}$, in a spectrophotometer (BEL Photonics UV-M51, Piracicaba, Brazil) previously calibrated with $80 \%$ ethanol. $0.5 \mathrm{~mL}$ of different dilutions of the pequi pulp extracts and $3.5 \mathrm{~mL}$ of the $\mathrm{ABTS}^{\cdot+}$ radical solution were placed in test tubes and homogenized in a tube shaker. After 6 min of reaction, the absorbance of the samples was read at $734 \mathrm{~nm}$. $80 \%$ ethanol was used as control, in replacement of the pequi extracts. The analysis was completely performed in low light environment. The antioxidant capacity was expressed by the TEAC value ( $\mu$ mol trolox $\mathrm{g}^{-1}$ pequi pulp), according to Rufino et al. ${ }^{22}$ calculated from the trolox analytical curve, prepared with standard solutions, with concentrations ranging between 10 and $100 \mu \mathrm{mol} \mathrm{L}{ }^{-1}$.

\section{Spectrophotometric assay of the DPPH${ }^{\bullet}$ radical}

The antioxidant capacity was determined by the DPPH 
test, according to the methodology described by BrandWilliams et al., ${ }^{28}$ with modifications.

In a low light environment, aliquots of $0.1 \mathrm{~mL}$ of different dilutions of pequi extracts were transferred to test tubes, which were added to $2.9 \mathrm{~mL}$ of $60 \mu \mathrm{mol} \mathrm{L}{ }^{-1}$ methanolic solution of the $\mathrm{DPPH}^{*}$ radical previously prepared. The mixture was then homogenized in a tube shaker. The tubes were placed to rest, in the dark, for $25 \mathrm{~min}$. Next, absorbance was read at $515 \mathrm{~nm}$ in a spectrophotometer (BEL Photonics UV-M51, Piracicaba, Brazil) previously calibrated with methanol. Methanol was used as the control, in replacement of the pequi extracts.

Similarly to the ABTS test, the results were expressed based on the TEAC value ( $\mu$ mol trolox $\mathrm{g}^{-1}$ pequi pulp), according to Rufino et al. ${ }^{22}$ Therefore, a trolox analytical curve was developed with standard solutions, with concentrations ranging from 30 to $600 \mu \mathrm{mol} \mathrm{L} \mathrm{L}^{-1}$.

\section{Statistical analysis}

The results for antioxidant capacity, expressed in TEAC and antioxidant capacity coefficient $(\mathrm{K})$ were presented as
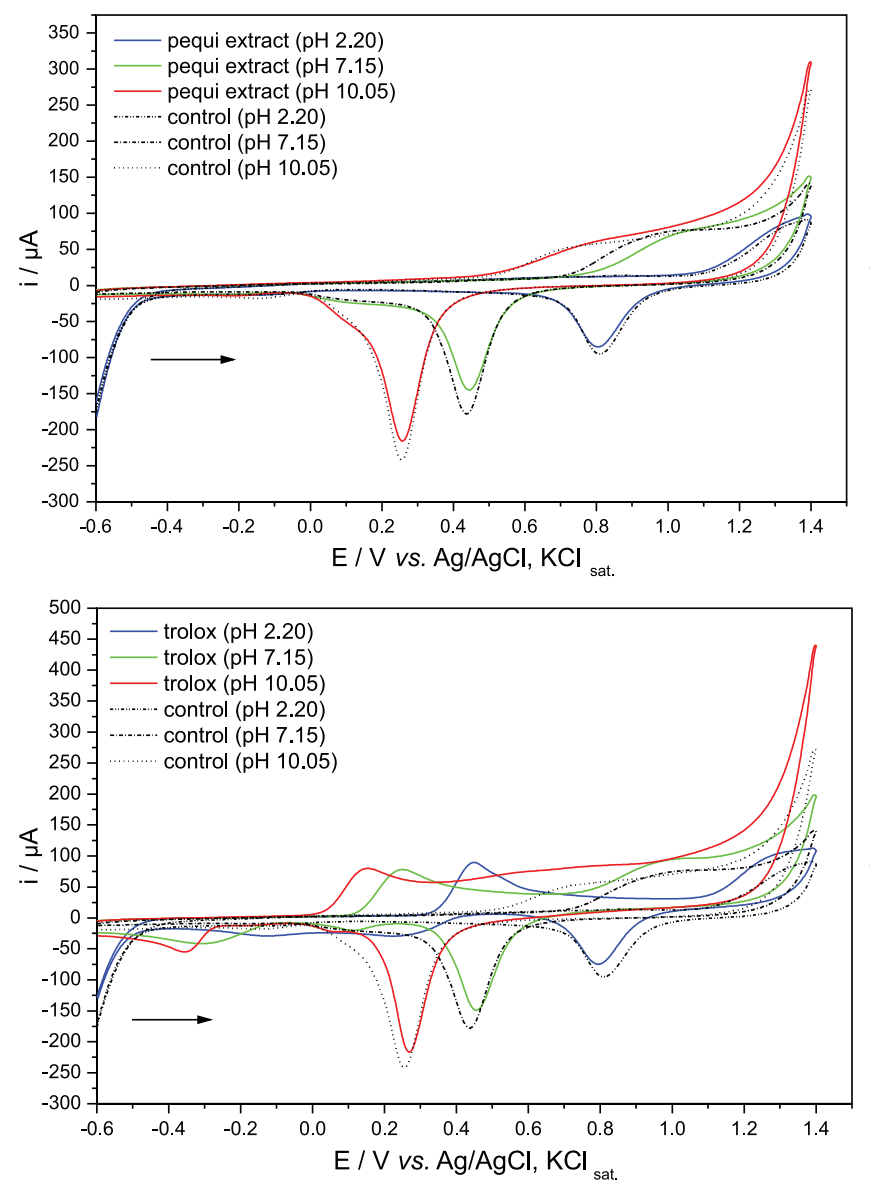

the mean ( \pm standard deviation) of the values obtained from three replicates. The statistical analyses were performed using analysis of variance (ANOVA), linear regression with no adjustment and Tukey test at 5\% probability, using the Statistical Analysis System (SAS), version 9.3, ${ }^{29}$ licensed for the Universidade Federal de Viçosa (Viçosa, MG, Brazil). A principal component analysis (PCA) was applied to produce graphics for better explaining the results found for the antioxidant compounds, according to $\mathrm{K}$ and $\mathrm{pH}$, using the Matlab platform. ${ }^{30}$

\section{Results and Discussion}

Characterization of the voltammetric profile of the compounds with antioxidant capacity

The voltammetric profile of the pequi pulp extract and antioxidant standards was assessed using the cyclic voltammetry technique, prior to the application of the experimental protocol, to evaluate the behavior of the oxygen electroreduction. Figure 1 shows the cyclic voltammograms for the pequi extract, L-ascorbic acid, BHA
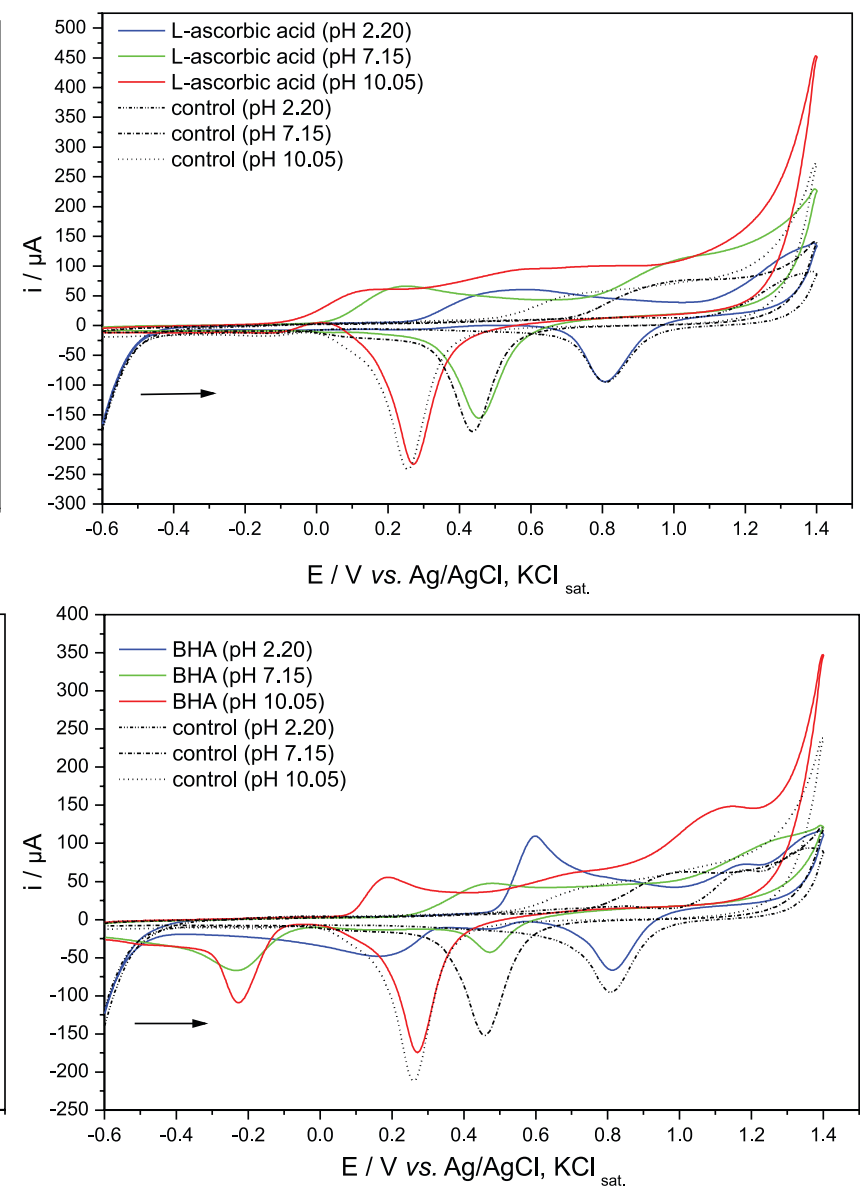

Figure 1. Cyclic voltammograms of pequi pulp extract and antioxidant standards L-ascorbic acid, BHA and trolox in $0.1 \mathrm{~mol} \mathrm{~L}^{-1} \mathrm{Britton}-\mathrm{Robinson}$ buffer, $\mathrm{pH} 2.20,7.15$ and 10.05. Scan of -0.6 to $+1.4 \mathrm{~V}$, at $100 \mathrm{mV} \mathrm{s}^{-1}$. Concentration of antioxidants standards: $1.0 \mathrm{mmol} \mathrm{L}^{-1}$. 
and trolox (the other figures are presented in the Figure S1, Supplementary Information).

Cathodic peaks with greater current intensity were observed, close to the potential of $0.810,0.440$ and $0.250 \mathrm{~V}$, at $\mathrm{pH} 2.20,7.15$ and 10.05 , respectively, in all compounds analyzed. These peaks are from the $0.1 \mathrm{~mol} \mathrm{~L}^{-1}$ Britton-Robinson buffer, as their intensity was similar to that of peaks obtained after the addition of the antioxidant standards and pequi pulp extract. Only BHA and trolox presented cathodic peaks that are not from the supporting electrolyte. The BHA showed better defined peaks, close to the potential $-0.200 \mathrm{~V}$ at $\mathrm{pH} 7.15$ and 10.05 .

Regarding the reading in the oxidation direction, all the analyzed compounds presented some anodic peak. Trolox (at $\mathrm{pH} 2.20,7.15$ and 10.05) and BHA (at pH 2.20 and 10.05) presented more defined peaks, with increased current intensity, which indicates increased sensitivity of the technique used for these compounds, since all antioxidant standards were analyzed in the same concentration $\left(1.0 \mathrm{mmol} \mathrm{L}^{-1}\right)$. It was also observed for these peaks that the $\mathrm{pH}$ affected the displacement of the potential for values closer to $0 \mathrm{~V}$, which improves the tendency of the antioxidant standard to oxidize, in the following order: $\mathrm{pH} 10.05>7.15>2.20$.

The potential variation can also be understood according to the Nernst equation (equation 1):

$\mathrm{E}=\mathrm{E}^{\mathrm{o}}-\frac{\mathrm{RT}}{\mathrm{nF}} \ln \frac{\text { [products }]}{\text { [reagents }]}$

where, $\mathrm{E}$ is the real potential (V) under nonstandard conditions; $\mathrm{E}^{\circ}$ is the tabulated standard potential $(\mathrm{V})$; $\mathrm{R}$ is the universal gas constant $\left(8.314 \mathrm{~J} \mathrm{~K}^{-1} \mathrm{~mol}^{-1}\right)$; $\mathrm{T}$ is the absolute temperature $(\mathrm{K})$; $\mathrm{n}$ is the number of electrons involved on the reaction stoichiometry; and $\mathrm{F}$ is the Faraday constant $\left(96,485 \mathrm{C} \mathrm{mol}^{-1}\right)$. It demonstrated that the potential depends on the concentration of the species in the solution and that it can be changed in case of variation in the concentration of the products formed, depending on the medium $\mathrm{pH}$. The same initial concentration has been used for all the antioxidant standards, but the structural change of the molecules varies differently for each compound (according to the $\mathrm{p} K_{\mathrm{a}}$, for instance), depending on the medium $\mathrm{pH}$. It can also make the redox reaction more thermodynamically favorable for certain substances.

In a study for the assessment of the antioxidant capacity of natural compounds, Arteaga et al. ${ }^{17}$ also verified that, as $\mathrm{pH}$ increased, the oxidation potentials changed to less positive values. It implies that oxidation becomes easier and may be related to the deprotonation of compounds. Alberto et al. ${ }^{31}$ also reported that the thermochemical viability of the electron transfer process (SET mechanism) of trolox increased with the degree of deprotonation of the antioxidant standard, for different free radicals.

The CV technique showed that all the evaluated compounds, except for BHA and trolox, were not electroactive at the range of 0 to $-0.6 \mathrm{~V}$, a potential window used for subsequent monitoring of the cathodic current of $\mathrm{O}_{2}$.

In vitro total antioxidant capacity assessment expressed by the antioxidant capacity coefficient $(\mathrm{K})$

Figure 2 shows the voltammograms of oxygen electroreduction in $0.1 \mathrm{~mol} \mathrm{~L}^{-1}$ Britton-Robinson buffer, $\mathrm{pH} 7.15$, with the addition of the pequi pulp extract. This Figure shows that the $\mathrm{O}_{2}$ current decreased as the pequi extract concentration $(\mathrm{a} \rightarrow \mathrm{g}$ ) increased. This behavior was also verified for the antioxidant standards for all $\mathrm{pH}$ values analyzed. The proportion of oxygen species in the solution decreases when it reacts with the antioxidant, according to the voltammetric readings, since less $\mathrm{O}_{2}$ molecules are available to receive electrons from the working electrode. Therefore, the intensity of the cathodic current of the oxidant decreases.

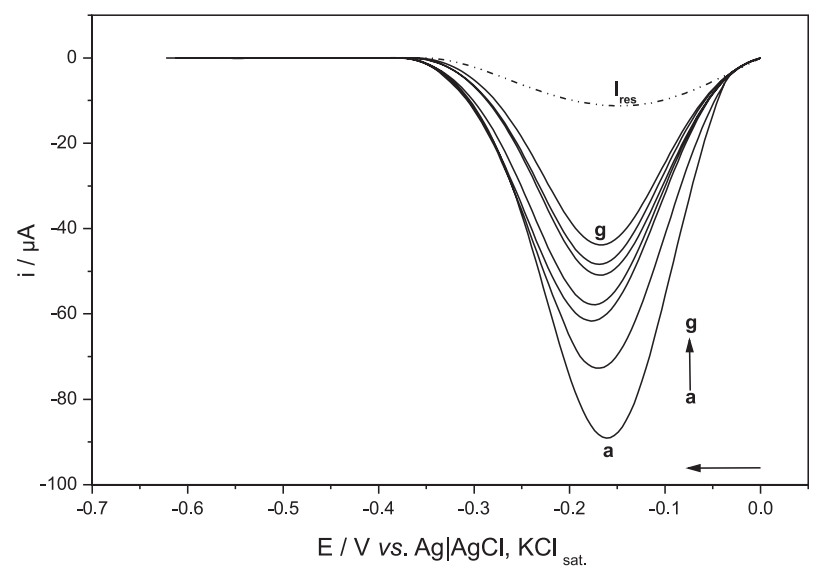

Figure 2. Differential pulse voltammograms of the oxygen electroreduction in $0.1 \mathrm{~mol} \mathrm{~L}^{-1}$ Britton-Robinson buffer, $\mathrm{pH} 7.15$; in the absence of extract of the pequi pulp (a) and with the addition of the extract ( $b$ to g), being (b) 50; (c) 100; (d) 150; (e) 200, (f) 250 and (g) $300 \mu \mathrm{L}$. $\mathrm{I}_{\text {res }}$ : residual current of the support electrolyte without addition of oxygen and of pequi pulp extract.

The effect of the increased antioxidant concentration was assessed (depending on the added volume) and the medium $\mathrm{pH}$ on the $\mathrm{O}_{2}$ current decay rate $\left[\left(\mathrm{I}_{\mathrm{pc}}-\mathrm{I}_{\mathrm{res}}\right) /\left(\mathrm{I}_{\mathrm{p} 0}-\mathrm{I}_{\mathrm{res}}\right)\right]$. No effect of the $\mathrm{pH}$ versus volume interaction $(p \geq 0.05)$ was observed. Therefore, the factors $\mathrm{pH}$ and volume worked independently and were studied separately for each sample with antioxidant capacity. Based on the averages of the current values obtained by voltammetric readings, a regression analysis was applied to the volume factor 
$\left[\left(\mathrm{I}_{\mathrm{pc}}-\mathrm{I}_{\mathrm{res}}\right) /\left(\mathrm{I}_{\mathrm{p} 0}-\mathrm{I}_{\mathrm{res}}\right) \times\right.$ compound volume added $]$. The $\mathrm{K}$ was determined for the evaluated compounds (Table 1) through the angular coefficient of each curve obtained in this analysis. Figure 3 presents the linear regression curves for the pequi extract, gallic acid, L-ascorbic acid and trolox.

Table 1 shows that the mean values of $\mathrm{K}$ ranged between
$0.768 \pm 0.112 \mathrm{~mL}^{-1}$ and $2.222 \pm 0.172 \mathrm{~mL}^{-1}$, respectively for $\alpha$-tocopherol ( $\mathrm{pH} 2.20)$ and L-ascorbic acid ( $\mathrm{pH} 10.05)$.

A principal component analysis of the antioxidant compounds depending on $\mathrm{K}$ and $\mathrm{pH}$ was applied (Figure 4) for better understanding of the results described in Table 1. The two first components explained $88.14 \%$.

Table 1. Antioxidant capacity coefficient $(\mathrm{K})$ for the pequi pulp extract and several antioxidant patterns (found in pequi and antioxidants recognized as reference standards), at different $\mathrm{pH}$ values

\begin{tabular}{lccc}
\hline \multirow{2}{*}{ Compound } & \multicolumn{3}{c}{${\text { Coefficient of antioxidant capacity } / \mathrm{mL}^{-1}}^{-}$} \\
\cline { 2 - 4 } Extract of pequi pulp & $\mathrm{pH} 2.20$ & $\mathrm{pH} 7.15$ & $\mathrm{pH} 10.05$ \\
L-Ascorbic acid & $1.719 \pm 0.202$ & $1.805 \pm 0.234$ & $1.704 \pm 0.139$ \\
Citric acid & $1.577 \pm 0.266$ & $1.542 \pm 0.121$ & $2.222 \pm 0.172$ \\
p-Coumaric acid & $1.676 \pm 0.476$ & $2.120 \pm 0.239$ & $2.006 \pm 0.297$ \\
Gallic acid & $2.149 \pm 0.084$ & $1.756 \pm 0.344$ & $1.587 \pm 0.241$ \\
$\alpha$-Tocopherol & $1.826 \pm 0.249$ & $1.523 \pm 0.315$ & $1.784 \pm 0.251$ \\
BHA & $0.768 \pm 0.112$ & $1.355 \pm 0.399$ & $1.527 \pm 0.448$ \\
BHT & $2.214 \pm 0.271$ & $1.486 \pm 0.109$ & $1.534 \pm 0.224$ \\
Trolox & $1.910 \pm 0.379$ & $1.620 \pm 0.210$ & $1.355 \pm 0.396$ \\
\hline
\end{tabular}

Mean values \pm standard deviation $(\mathrm{n}=3$ ). BHA: 2(3)-t-butyl-4-hydroxyanisole; BHT: 2,6-di-tert-butyl-4-methylphenol.
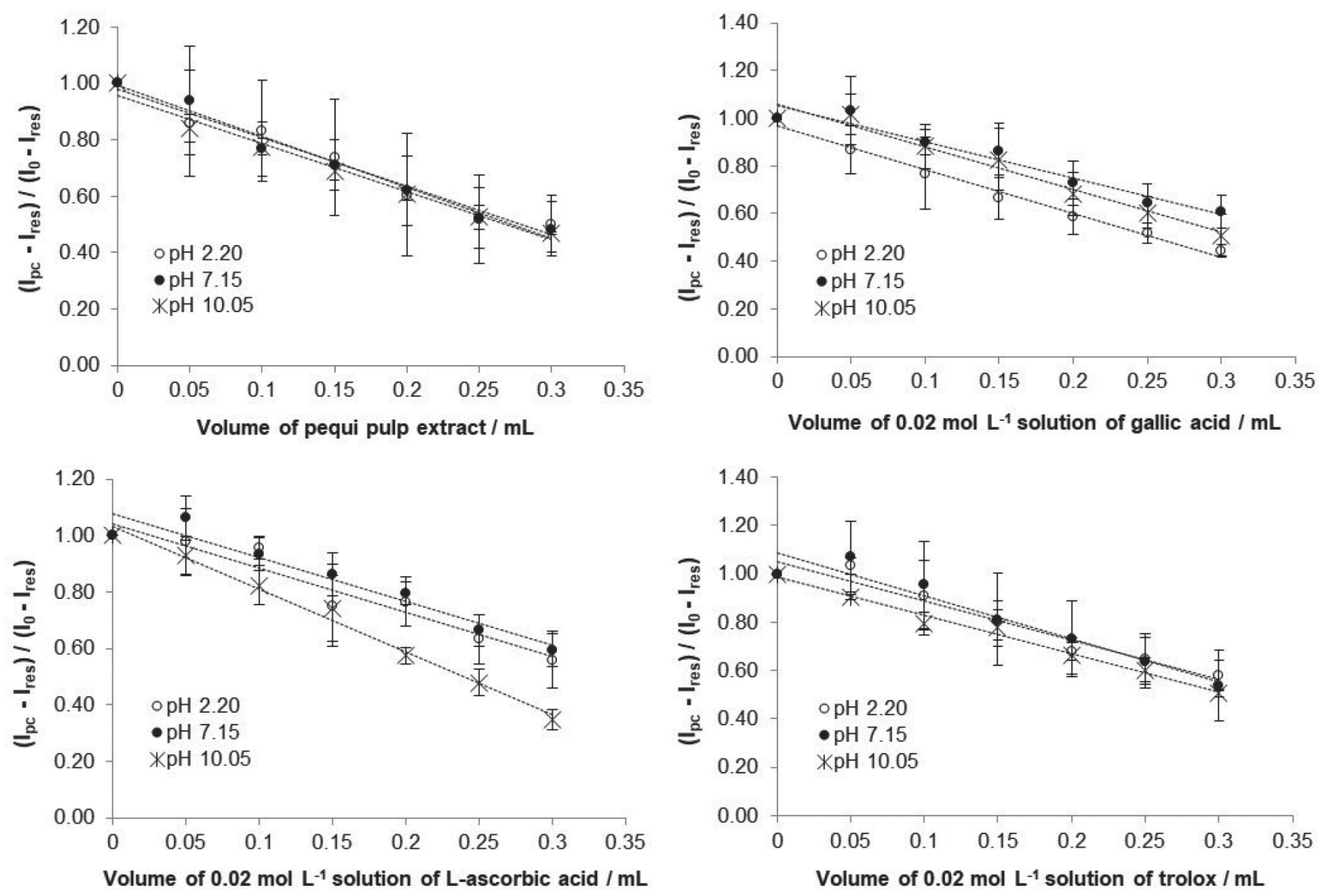

Figure 3. Variation curves of cathodic oxygen current rate as a function of the volume of pequi pulp extract and $0.02 \mathrm{~mol} \mathrm{~L}^{-1}$ solution of compounds with antioxidant capacity (gallic acid, L-ascorbic acid and trolox) in $0.1 \mathrm{~mol} \mathrm{~L}^{-1}$ Britton-Robinson buffer, $\mathrm{pH} 2.20,7.15$ and 10.05. 

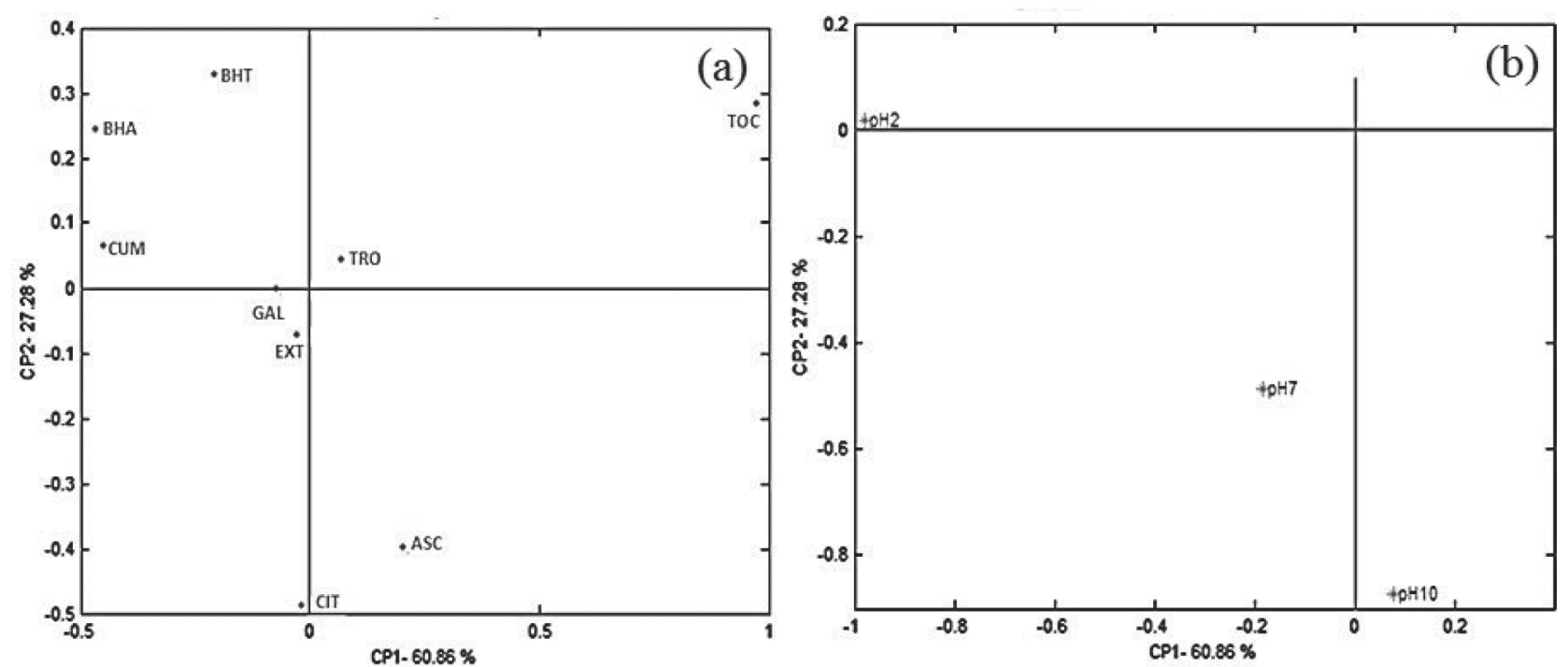

Figure 4. Principal components analysis: pequi extract and antioxidant compounds as a function of $\mathrm{pH}$ and antioxidant capacity coefficient (a), and $\mathrm{pH}$ as a function of extract and compounds analyzed (b). Legend: EXT: pequi pulp extract; ASC: L-ascorbic acid; CIT: citric acid; CUM: $p$-coumaric acid; GAL: gallic acid; TOC: $\alpha$-tocopherol; BHA: butyl hydroxyanisole, BHT: butyl hydroxytoluene; TRO: trolox.

Figure 4 shows the distribution of the antioxidants in relation to the principal components (a) and a projection of the groups in relation to $\mathrm{pH}(\mathrm{b})$. The simultaneous assessment of Figures $4 \mathrm{a}$ and $4 \mathrm{~b}$ reveals a distribution of the antioxidant compounds, according to the $\mathrm{K}$ and $\mathrm{pH}$ values. Therefore, it is possible to infer that the compounds $p$-coumaric acid, BHA and BHT presented better antioxidant behavior at $\mathrm{pH}$ 2.20; L-ascorbic acid, at $\mathrm{pH}$ 10.05; and pequi extract and citric acid, at $\mathrm{pH}$ 7.15. The other $\mathrm{pH}$ values seem to affect the pequi extract, which was also verified for citric acid, in relation to $\mathrm{pH} 10.05$. The antioxidant capacity of gallic acid was affected by $\mathrm{pH} 2.20$ and 7.15 .

The increased antioxidant capacity observed at more alkaline $\mathrm{pH}$ values is directly related to the deprotonation of certain compounds, and may involve different mechanisms of antioxidant capacity, such as the donation of hydrogen atom or electrons, or the coexistence of both mechanisms. ${ }^{32}$ In this work, this justification can be attributed to the ascorbic and citric acids, since the greater antioxidant tendency of these compounds was verified at $\mathrm{pH}$ values in which both were deprotonated.

Figure 4 shows that the compound $\alpha$-tocopherol presented the greatest difference among those analyzed, which may be explained by its lower solubility in the supporting electrolyte, compared to the other compounds under study.

The antioxidant capacity of trolox and $\alpha$-tocopherol standards was not affected by $\mathrm{pH}$ under the experimental conditions of the present study. It can be explained by the fact that the $\mathrm{K}$ value is directly related to the reaction stoichiometry (how much oxygen reacts with an antioxidant molecule), which is not necessarily altered by the medium $\mathrm{pH}$ variation (differently from that described for the potential), since $\mathrm{K}$ also depends on the reaction kinetics.

It must be highlighted that the distribution of the antioxidant standards may be related to the similarity of the chemical structure of the compounds. Among the compounds assessed, greater structural similarity was found between trolox and $\alpha$-tocopherol, and between BHA and BHT.

Figure 4 shows that BHA, BHT and $p$-coumaric acid seem to present similar characteristics for the antioxidant capacity, which may be related to the presence of a phenol group in the chemical structure of these compounds.

Ahmed and Shakee ${ }^{33}$ state that the behavior and the intensity of the reduction of the oxidizing agent vary according to the structure of the antioxidant compounds. These authors attributed the variation in the mode and magnitude of elimination of the superoxide radical to the structure-activity relationship of different flavonoids: the presence of phenol groups in the chemical structure of the molecule, which increases its antioxidant capacity; as well as the presence of a planar structure and unsaturations, since they enhance the stability of the phenoxyl radical formed.

Figure 4 shows that the pequi pulp extract and the gallic acid presented similar distribution. Therefore, based on the values of the antioxidant capacity coefficient obtained in this study, the antioxidant capacity of the pequi extract can be strongly attributed to the presence of gallic acid in its composition, compared to the other antioxidant standards assessed. Gallic acid was described as the predominant compound among the phenolic compounds evaluated by Machado et al. ${ }^{34}$ in the aqueous extract 
of pequi pulp (from the region of Montes Claros, MG, Brazil). Almeida et al..$^{35}$ identified gallic acid, by using HPLC-DAD-MS (high-performance liquid chromatography with diode array detection coupled to mass spectrometry), as the major phenolic compound observed in the lyophilized pequi pulp, corresponding to $31 \%$ of the total phenolics.

The antioxidant potential of gallic acid was also observed in a study carried out by Arteaga et al.,${ }^{17}$ which highlighted the presence of adjacent phenolic groups, prone to oxidation, and a carboxyl group that favors the stabilization of the species resulting from the oxidative process.

\section{In vitro evaluation of the total antioxidant capacity expressed in DPV ${ }_{\text {TEAC }}, A B T S_{\text {TEAC }}$ and DPPH}

Figure 5 presents the results of the antioxidant capacity of pequi pulp, evaluated by the DPV, ABTS and DPPH tests, expressed in trolox standard, TEAC value ( $\mu \mathrm{mol}$ of trolox $\mathrm{g}^{-1}$ pequi pulp). This Figure shows that the greatest antioxidant capacity was obtained by the DPV electrochemical test $\left(53.43 \pm 5.14 \mu \mathrm{mol}\right.$ trolox $\mathrm{g}^{-1}$ pulp), in comparison with the ABTS spectrophotometric tests $\left(7.62 \pm 0.66 \mu \mathrm{mol}\right.$ trolox $\mathrm{g}^{-1}$ pulp) and DPPH $\left(8.88 \pm 1.08 \mu\right.$ mol trolox $\mathrm{g}^{-1}$ pulp).

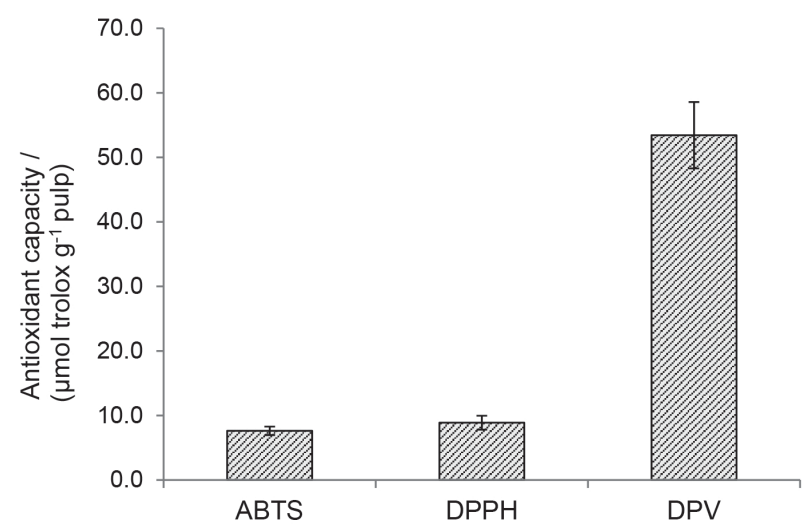

Figure 5. Antioxidant capacity of pequi pulp expressed in trolox equivalent (wet basis), according to electrochemical differential pulse voltammetry (DPV) and spectrophotometric assays of the radical cation $\mathrm{ABTS}^{++}$and the radical DPPH. Mean \pm standard deviation $(n=3)$.

Nascimento et al. ${ }^{36}$ assessed pequi from São Miguel do Araguaia, GO, Brazil, by the DPPH test and found $12.0 \mu \mathrm{mol}$ trolox $\mathrm{g}^{-1}$ of lyophilized pequi pulp. Rufino et $\mathrm{al}^{37}$ conducted a study to evaluate the antioxidant capacity of tropical nontraditional Brazilian fruits and found values ranging from $6.3 \pm 0.2$ to $153.0 \pm 2.6 \mu \mathrm{mol}$ trolox g ${ }^{-1}$ of fruit, respectively, for umbu and camu-camu, using the ABTS test.

It is known that the total antioxidant capacity of a food matrix is affected by the synergistic activity of its bioactive components. ${ }^{32}$ Therefore, the best result was found by the DPV test, possibly because this technique allows the joint evaluation of the reducing power of pequi bioactive components (phenolic compounds, ascorbic acid and carotenoids). On the other hand, the ABTS and DPPH tests are more specific for polyphenols, and may underestimate the value obtained. The higher sensitivity of the voltammetric electrochemical test applied in this study can also be attributed to the thermodynamic enhancement of the reaction mechanism involved between the antioxidant compounds of pequi and oxygen (oxidizing agent).

Sawai et al $^{38}$ state that the DPPH' radical test is not the most appropriate to evaluate the antioxidant potential of lipophilic compounds, including carotenoids. Therefore, this trial is more efficient to evaluate the antioxidant capacity of phenolic compounds, and it underestimates the antioxidant capacity of pequi pulp.

Schaich et al. ${ }^{39}$ mentioned several factors that limit the use of the ABTS and DPPH tests, such as disregard for chemical aspects, including the effects of solvents, concentration, medium $\mathrm{pH}$, radical solubility and, particularly, reaction kinetics; use of stable radicals with stereochemical with hindrance instead of easy access and short duration small radicals (example: $\mathrm{OH}^{\cdot}$ and $\mathrm{O}_{2}^{-*}$ ), for better simulation of in vivo occurrence; and lack of standardization of the experimental procedures, especially the expression of the results, which prevents comparing the results from different researchers.

Besides, the spectrophotometric assays ABTS and DPPH are affected by the activity of interfering agents present in the food matrix. Oliveira et al. ${ }^{4}$ described the ascorbic acid as an interfering agent in the evaluation of the antioxidant capacity of anthocyanins in foods. Schaich et al. ${ }^{39}$ cited the interference caused by the oxygen dissolved in the medium and the use of organic solvents (for instance, methanol in the DPPH test).

The antioxidant capacity of a matrix is affected by several factors, such as solubility and the chemical structure of the bioactive compounds, chemical quality of the oxidizing agent, reaction mechanism, specific experimental conditions, among others. Therefore, it is difficult to compare the TEAC values obtained by different tests, since the different results can be attributed to the characteristics of each technique. ${ }^{40}$

Arteaga et al. ${ }^{17}$ report that the electrochemical tests are more advantageous than the DPPH test, since they present greater precision and speed of analysis; the tests can be carried out at different $\mathrm{pH}$ values, and on different reaction media, which allows the comparison between the antioxidant capacities of molecules under different experimental conditions; they are less expensive, mainly 
due to the use of less organic solvents, which also reduces the waste generated.

Therefore, the voltammetric test is a viable alternative for the evaluation of the antioxidant capacity of food matrices.

\section{Conclusions}

The results obtained in this study lead to the inference that the pequi pulp has potential to work as a reducing agent when compared to the antioxidant standards evaluated. Its antioxidant capacity was strongly attributed to the presence of gallic acid in its composition. Besides, it was observed that the $\mathrm{pH}$ of solution affects the activity of most antioxidant compounds and cannot be neglected in such analyses.

Among the three in vitro assays applied, ABTS, DPPH and DPV, the best result for antioxidant capacity of the pequi pulp was obtained by the voltammetric test and expressed in trolox standard equivalent. Therefore, this protocol was efficient to evaluate the antioxidant capacity. It is also an alternative methodology to carry out this analysis, mainly for providing relevant information for the redox process that cannot be obtained from the traditional spectrophotometric assays.

\section{Supplementary Information}

Supplementary information is available free of charge at http://jbcs.org.br as a PDF file.

\section{Acknowledgments}

The authors are grateful to financial support from the Conselho Nacional de Desenvolvimento Científico e Tecnológico (CNPq, Brazil), Fundação de Amparo à Pesquisa do Estado de Minas Gerais (FAPEMIG, Brazil) and Instituto Federal de Educação, Ciência e Tecnologia do Espírito Santo (IFES, Brazil).

\section{References}

1. Shahidi, F.; Zhong, Y.; J. Funct. Foods 2015, 18, 757.

2. Apak, R.; Özyürek, M.; Güçlü, K.; Çapanoğlu, E.; J. Agric. Food Chem. 2016, 64, 997.

3. Apak, R.; Özyürek, M.; Güçlü, K.; Çapanoğlu, E.; J. Agric. Food Chem. 2016, 64, 1028.

4. Oliveira, I. R. N.; Teófilo, R. F.; de Oliveira, E. B.; Ramos, A. M.; Barros, F. A. R.; Maia, M. P.; Stringheta, P. C.; Int. J. Food Sci. Technol. 2017, 52, 511.

5. Alves, C. Q.; David, J. M.; David, J. P.; Bahia, M. V.; Aguiar, R. M.; Quim. Nova 2010, 33, 2202.
6. Dar, R. A.; Brahman, P. K.; Khurana, N.; Wagay, J. A.; Lone, Z. A.; Ganaie, M. A.; Pitre, K. S.; Arab. J. Chem. 2017, 10, S1119.

7. Halliwell, B.; Lancet 2000, 355, 1179.

8. de Macêdo, I. Y. L.; Garcia, L. F.; Oliveira-Neto, J. R.; Leite, K. C. S.; Ferreira, V. S.; Ghedini, P. C.; Gil, E. S.; Food Chem. 2017, 217, 326.

9. Peixoto, C. R. M.; Fraga, S.; Justim, J. R.; Gomes, M. S.; Carvalho, D. G.; Jarenkow, J. A.; Moura, N. F.; J. Electroanal. Chem. 2017, 799, 519.

10. Cruz, D.; Barroso, M. F.; Ramalhosa, M. J.; Coelho, A.; da Silva, H.; Duarte, A. J.; González-García, M. B.; Carvalho, A. P.; Delerue-Matos, C.; J. Electroanal. Chem. 2016, 763, 110.

11. Falcão, S. I.; Tomás, A.; Freire, C.; Vilas-Boas, M.; Eur. Food Res. Technol. 2016, 242, 1393.

12. Ferreira, R. D. Q.; Greco, S. J.; Delarmelina, M.; Weber, K. C.; Electrochim. Acta 2015, 163, 161.

13. Lugonja, N. M.; Stanković, D. M.; Miličić, B.; Spasić, S. D.; Marinković, V.; Vrvić, M. M.; Food Chem. 2018, 240, 567.

14. Hoyos-Arbeláez, J.; Vázquez, M.; Contreras-Calderón, J.; Food Chem. 2017, 221, 1371.

15. Oliveira-Neto, J. R.; Rezende, S. G.; Reis, C. F.; Benjamin, S. R.; Rocha, M. L.; Gil, E. S.; Food Chem. 2016, 190, 506.

16. David, I. G.; Bizgan, A. M. C.; Popa, D. E.; Buleandra, M.; Moldovan, Z.; Badea, I. A.; Tekiner, T. A.; Basaga, H.; Ciucu, A. A.; Food Chem. 2015, 173, 1059.

17. Arteaga, J. F.; Ruiz-Montoya, M.; Palma, A.; Alonso-Garrido, G.; Pintado, S.; Rodríguez-Mellado, J. M.; Molecules 2012, 17, 5126.

18. Alves, A. M.; Fernades, D. C.; Sousa, A. G. O.; Naves, R. V.; Naves, M. M. V.; Braz. J. Food Technol. 2014, 17, 198.

19. Machado, M. T. C.; Mello, B. C. B. S.; Hubinger, M. D.; J. Food Eng. 2013, 117, 450.

20. Ribeiro, D. M.; Fernandes, D. C.; Alves, A. M.; Naves, M. M. V.; Food Sci. Technol. 2014, 34, 507.

21. Azevedo-Meleiro, C. H.; Rodriguez-Amaya, D. B.; J. Food Compos. Anal. 2004, 17, 385.

22. Rufino, M. S. M.; Alves, R. E.; de Brito, E. S.; Morais, S. M.; Sampaio, C. G.; Pérez-Jiménez, J.; Saura-Calixto, F. D.; Comun. Tec. - EMBRAPA, Cent. Pesqui. Agropec. Trop. Umido 2007, 128, 1. Available at https://www.infoteca.cnptia.embrapa. br/infoteca/bitstream/doc/426954/1/Cot128.pdf, accessed in February 2018.

23. Korotkova, E. I.; Karbainov, Y. A.; Shevchuk, A. V.; J. Electroanal. Chem. 2002, 518, 56.

24. Zoski, C. G.; Handbook of Electrochemistry, $4^{\text {th }}$ ed.; Elsevier: Amsterdam, Netherlands, 2007.

25. Solomons, T. W. G.; Fryhle, C. B.; Química Orgânica, vol. 1, $10^{\mathrm{a}}$ ed.; LTC: Rio de Janeiro, Brasil, 2016.

26. OriginLab, version 8.0; OriginLab Corp., Northampton, MA, USA, 2007. 
27. Re, R.; Pellegrini, N.; Proteggente, A.; Pannala, A.; Yang, M.; Rice-Evans, C.; Free Radic. Biol. Med. 1999, 26, 1231.

28. Brand-Williams, W.; Cuvelier, M. E.; Berset, C.; LWT - Food Sci. Technol. 1995, 28, 25.

29. Statistical Analysis System, SAS Procedures Guide, version 9.3; SAS Institute Inc., Cary, NC, USA, 2011.

30. Matlab R2016a, version 9.0; The MathWorks Inc., Natick, MA, USA, 2016.

31. Alberto, M. E.; Russo, N.; Grand, A.; Galano, A.; Phys. Chem. Chem. Phys. 2013, 15, 4642.

32. Altunkaya, A.; Gökmen, V.; Skibsted, L. H.; Food Chem. 2016, $190,25$.

33. Ahmed, S.; Shakeel, F.; Czech J. Food Sci. 2012, 30, 153.

34. Machado, M. T. C.; Mello, B. C. B. S.; Hubinger, M. D.; Food Bioprod. Process. 2015, 95, 304.
35. Almeida, M. R.; Darin, J. D. C.; Hernandes, L. C.; Aissa, A. F.; Chisté, R. C.; Mercadante, A. Z.; Antunes, L. M. G.; Bianchi, M. L. P.; Plant Foods Hum. Nutr. 2012, 67, 171.

36. do Nascimento, N. R. R.; Alves, A. M.; Silva, M. R.; Naves, M. M. V.; Rev. Bras. Frutic. 2017, 39, 1.

37. Rufino, M. S. M.; Alves, R. E.; de Brito, E. S.; Pérez-Jiménez, J.; Saura-Calixto, F.; Mancini-Filho, J.; Food Chem. 2010, 121, 996.

38. Sawai, Y.; Moon, J. H.; Sakata, K.; Watanabe, N.; J. Agric. Food Chem. 2005, 53, 3598.

39. Schaich, K. M.; Tian, X.; Xie, J.; J. Funct. Foods 2015, 14, 111.

40. Cárdenas, A.; Gómez, M.; Frontana, C.; J. Electroanal. Chem. 2014, 729, 116.
Submitted: November 9, 2017

Published online: March 6, 2018 